\title{
Anticancer efficacy enhancement and attenuation of side effects of doxorubicin with titanium dioxide nanoparticles
}

This article was published in the following Dove Press journal:

International Journal of Nanomedicine

14 October 201।

Number of times this article has been viewed

\author{
Yan Chen 1,* \\ Ying Wan ${ }^{1, *}$ \\ Yi Wang' \\ Haijun Zhang ${ }^{2}$ \\ Zhijun Jiao' \\ 'Key Laboratory of Medical \\ Immunology and Department of \\ Laboratory Medicine, Affiliated \\ Hospital of Jiangsu University, \\ Zhenjiang; ${ }^{2}$ Department of Oncology, \\ Zhongda Hospital, Medical School, \\ Southeast University, Nanjing, People's \\ Republic of China \\ *These authors have contributed \\ equally to this work
}

Correspondence: Zhijun Jiao

Key Laboratory of Medical Immunology and Department of Laboratory Medicine, Affiliated Hospital of Jiangsu University, Zhenjiang, People's Republic of China

Tel +865 II 8502 II 35

Fax +865 II 8502 II 35

Email jiaozhijun@ujs.edu.cn
Background: Doxorubicin has a broad spectrum of anticancer activity, but its clinical application is limited due to serious side effects. The aim of this study was to explore a novel drug delivery system based on titanium dioxide $\left(\mathrm{TiO}_{2}\right)$ nanoparticles for its potential role in enhancing the anticancer efficacy of doxorubicin while reducing its side effects.

Methods and results: Doxorubicin was loaded into $\mathrm{TiO}_{2}$ nanoparticles by forming complexes with the transition metal, titanium, to construct doxorubicin-titanium dioxide ( $\left.\mathrm{DOX}-\mathrm{TiO}_{2}\right)$ nanocomposites as a drug delivery system. The anticancer activity of the $\mathrm{DOX}-\mathrm{TiO}_{2}$ nanocomposites was demonstrated by MTT assay, and the possible signaling pathway was explored by Western blot. In human SMMC-7721 hepatocarcinoma cells, our observations demonstrated that this drug delivery system markedly increased the efficiency of drug per dosage and decreased the $\mathrm{IC}_{50}$, resulting in anticancer efficacy enhancement and side effect attenuation.

Conclusion: Such a doxorubicin delivery strategy is promising in cancer therapy. Apoptosis may contribute to the mechanism, due to protein expression of $\mathrm{Bcl}-2$ being downregulated and that of Bax and caspase 3 being upregulated.

Keywords: doxorubicin, titanium dioxide nanoparticles, drug delivery system, apoptosis

\section{Introduction}

Doxorubicin is one of the most effective anticancer drugs to date, with a wide scope of activity in human cancers, including acute lymphoblastic leukemia, breast carcinoma, ovarian carcinoma, and hepatocellular carcinoma. ${ }^{1}$ However, its clinical application is limited by its harmful side effects, the most significant of which is its cardiotoxicity, which can lead to cardiomyopathy and congestive heart failure. ${ }^{2}$ Overcoming side effects is the greatest challenge for doxorubicin before its clinical application. Therefore, efforts have been made to develop new delivery techniques to reduce side effects, which could alter its biodistribution, enhance its deposition at the tumor sites, and improve its therapeutic efficacy. The availability of a nanocarrier drug delivery system is an exciting development that holds the promise of a fundamental change in cancer chemotherapy. ${ }^{3,4}$

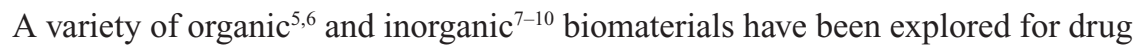
delivery purposes, among which the semiconductor nanomaterials, such as titanium dioxide $\left(\mathrm{TiO}_{2}\right)$ nanoparticles and zinc oxide nanorods, are attracting an increasing level of attention. ${ }^{1-15}$ Barick et al reported a method for entrapping drugs at sites capable of complexing with transition metal ions and suggested that drug release is dependent on the $\mathrm{pH}$ of the medium and the nature of the materials which encapsulate the drug. ${ }^{12}$ It is also suggested that this general strategy could be readily extended to other inorganic carriers. ${ }^{12}$ 
In light of these observations, we explored a novel drug delivery system based on $\mathrm{TiO}_{2}$ nanoparticles for doxorubicin by a simple and easy scheme to enhance its chemotherapeutic efficiency and reduce the side effects. To the best of our knowledge, no study of doxorubicin has been carried out using $\mathrm{TiO}_{2}$ nanoparticles for anticancer efficacy enhancement and side effect attenuation. In this study, doxorubicin was loaded on $\mathrm{TiO}_{2}$ nanoparticles which are chemically stable, environmentally friendly, and noncytotoxic, ${ }^{13,14}$ to form nanocomposites of doxorubicin-loaded titanium dioxide nanoparticles $\left(\mathrm{DOX}-\mathrm{TiO}_{2}\right)$ for a drug delivery system. Their encapsulation efficiency and loading efficiency was assessed by high-pressure liquid chromatography. We then identified the cytotoxic effects of $\mathrm{DOX}-\mathrm{TiO}_{2}$ in human SMMC-7721 hepatocarcinoma cells. The mechanism of anticancer efficacy enhancement and side effect attenuation were also investigated.

\section{Materials and methods}

\section{Main chemicals and apparatus}

Doxorubicin was purchased from Hisun Phamaceuticals, Zhejiang, China, and a stock solution was freshly prepared and stored in the dark at $4{ }^{\circ} \mathrm{C}$. Phosphate-buffered solution (0.1 M, pH 7.2) was prepared with double-distilled water. $\mathrm{TiO}_{2}$ nanoparticles purchased from Degussa Corporation (Parsippany, NJ) were suspended in sterilized phosphatebuffered solution. Monoclonal antibodies, including Bax, Bcl-2, caspase 3, and $\beta$-actin, were purchased from Santa Cruz Biotechnology (Santa Cruz, CA). The horseradish peroxidase-conjugated IgG antibody was obtained from Nanjing KeyGenBiotech Inc (Nanjing, China). 4, 6-diamidino2-phenylindole (DAPI) and 3-(4, 5-dimethylthiazol-2-yl)-2, 5-diphenyltetrazolium bromide (MTT) were obtained from Sigma (St Louis, MO) and stored in the dark. All other reagents were of analytical grade. The optical density at $492 \mathrm{~nm}$ was recorded by a multiwell spectrophotometer reader (DG5033A, Nanjing, China). Transmission electron microscope images were obtained using a JEM-2100 transmission electron microscope (JOEL, Peabody, MA).

\section{Construction of $\mathrm{DOX}-\mathrm{TiO}_{2}$ nanocomposites}

For a typical drug loading experiment, a $2 \mathrm{~mL}$ aqueous solution of doxorubicin $(2 \mathrm{mg} / \mathrm{mL})$ was added to a $1 \mathrm{~mL}$ aqueous suspension of $\mathrm{TiO}_{2}$ nanoparticles $(10 \mathrm{mg} / \mathrm{mL})$. The reaction mixture was kept overnight in the dark to construct the nanocomposites of $\mathrm{DOX}-\mathrm{TiO}_{2}$, which acted as a drug delivery system. The zeta potential of the $\mathrm{TiO}_{2}$ nanoparticles and $\mathrm{DOX}-\mathrm{TiO}_{2}$ nanocomposites was determined to confirm the interaction of doxorubicin loading onto the $\mathrm{TiO}_{2}$ nanoparticles. Doxorubicin-loaded $\mathrm{TiO}_{2}$ nanoparticles were separated from the free-standing drug molecules by centrifugation at $5000 \mathrm{~g}$ for 20 minutes and the supernatant was determined by high-pressure liquid chromatography, allowing estimation of the drug encapsulation efficiency and loading efficiency. The encapsulation efficiency and loading efficiency were calculated using the following equations:

Encapsulation efficiency $=$ (amount of drug in drug-loaded nanoparticles/initial amount of drug) $\times 100 \%$

Loading efficiency $=$ (amount of drug in drug-loaded nanoparticles/total amount of drug-loaded nanoparticles) $\times 100 \%$

\section{Cell culture}

Human SMMC-7721 hepatocarcinoma cells were obtained from the Shanghai Institute of Cells, Chinese Academy of Sciences, and maintained in RPMI 1640 (Gibco, Grand Island, NY) medium supplemented with $10 \%$ heat-inactivated fetal bovine serum, $100 \mathrm{U} / \mathrm{mL}$ penicillin, and $100 \mu \mathrm{g} / \mathrm{mL}$ streptomycin (Sigma) at $37^{\circ} \mathrm{C}$ in humidified air with $5 \% \mathrm{CO}_{2}$.

\section{Assay of anticancer activity}

The cytotoxicity of the $\mathrm{TiO}_{2}$ nanoparticles, doxorubicin, and DOX- $-\mathrm{TiO}_{2}$ was studied in the human SMMC-7721 hepatocarcinoma cell line by MTT assay. Cells at $1 \times 10^{5} / \mathrm{mL}$ were seeded in 96-well plates and incubated for 24 hours. The growth medium was then replaced with $200 \mu \mathrm{L}$ of the prepared medium containing free doxorubicin or $\mathrm{DOX}-\mathrm{TiO}_{2}$, in which the doxorubicin concentration was $0,0.125,0.25$, 0.5 , and $1 \mu \mathrm{g} / \mathrm{mL}$. The cells were also treated with $\mathrm{TiO}_{2}$ nanoparticles alone to evaluate cytotoxicity. Untreated cells were used as the control group. The cells were further incubated for 48 hours, and the relative anticancer activity was assessed using MTT assays. In brief, MTT solutions were added after the treatments and incubated for an additional four hours. Dimethyl sulfoxide was added to solubilize the formazan crystal, and optical density at $492 \mathrm{~nm}$ was recorded. The cell viability fraction (\%) was calculated as follows:

$$
\mathrm{OD}_{492 \mathrm{~nm} \text { in test cells }} / \mathrm{OD}_{492 \mathrm{~nm} \text { in control cells }} \times 100 \%
$$

\section{Western blot analysis}

Expression of apoptosis-related proteins was detected by Western blot after the different treatments. In brief, total protein was isolated and subjected to sodium dodecyl sulfate polyacrylamide gel electrophoresis, and transferred to 
a polyvinylidene fluoride membrane. After being blocked, the membrane was incubated with primary monoclonal antibodies, either anti-Bax, Bcl-2, caspase 3 , or anti- $\beta$-actin overnight at $4{ }^{\circ} \mathrm{C}$, and subsequently incubated with horseradish peroxidase-conjugated $\operatorname{IgG}$ antibody as the secondary antibody for one hour at room temperature. The protein bands were detected by an enhanced ECL detection system (Amersham, UK). After normalization by the corresponding expression of $\beta$-actin, protein expression levels of caspase 3 , Bax, and Bcl-2 were determined by densitometry scans.

\section{Statistical analysis}

All the data are presented as the mean \pm standard deviation. The F-test was used for significance testing, and $P<0.05$ was considered to be statistically significant. All tests were performed using SPSS version 13.0 (SPSS Inc, Chicago, IL).

\section{Results and discussion Characterization of $\mathrm{TiO}_{2}$ nanoparticles}

A representative transmission electron microscopic image of the $\mathrm{TiO}_{2}$ nanoparticles is shown in Figure 1. The particles had a spherical shape with a diameter of about $25 \mathrm{~nm}$. The size distribution of the $\mathrm{TiO}_{2}$ nanoparticles is shown in Figure 2. The particles had dimensions suitable for escaping rapid renal excretion, as well as avoiding components of the reticular endothelial system, thus facilitating potentially passive targeting of drugs to tumors via the enhanced permeation and retention effect and increasing drug accumulation in tumor cells after endocytosis. ${ }^{16}$

\section{Drug carrier role of $\mathrm{TiO}_{2}$ nanoparticles}

Previous investigations showed that doxorubicin has three potential metal binding sites. One is the nitrogen atom in

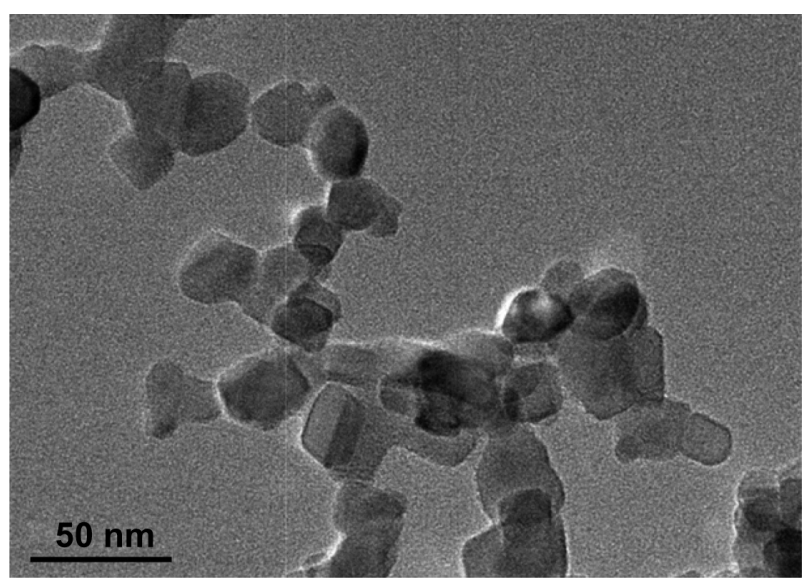

Figure I Transmission electron microscope image of magnetic titanium oxide nanoparticles.

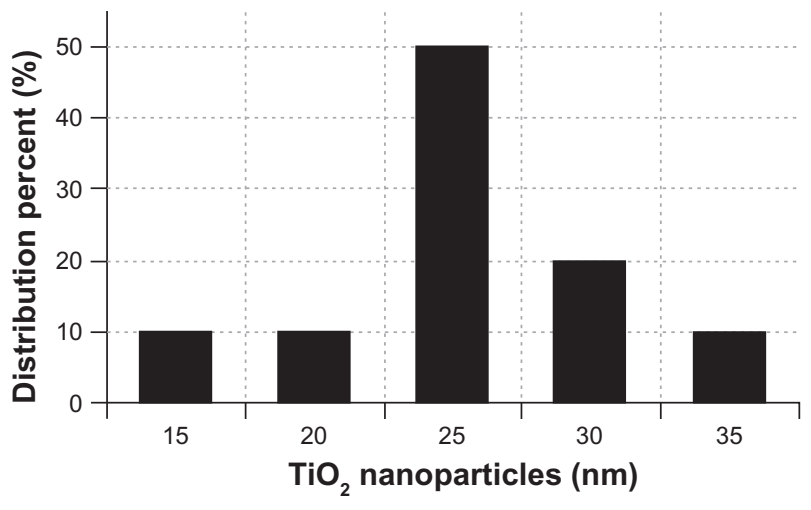

Figure 2 Size distribution histogram of titanium oxide nanoparticles.

the sugar moiety and the other two are the chelating sites of the quinone and the phenolic oxygens on both sides of the anthracycline aromatic moiety. ${ }^{12}$ In the present study, we explored the ability of $\mathrm{TiO}_{2}$ nanoparticles to act as a drug carrier for loading doxorubicin. As shown in Figure 3A, we observed the color change of pure doxorubicin from red to pink during the loading process, indicating that doxorubicin molecules can form complexes with $\mathrm{TiO}_{2}$ nanoparticles, forming $\mathrm{DOX}-\mathrm{TiO}_{2}$ nanocomposites as a drug delivery system due to the interaction of doxorubicin with $\mathrm{TiO}_{2}$. Figure 3B shows a proposed schematic representation of doxorubicin loading

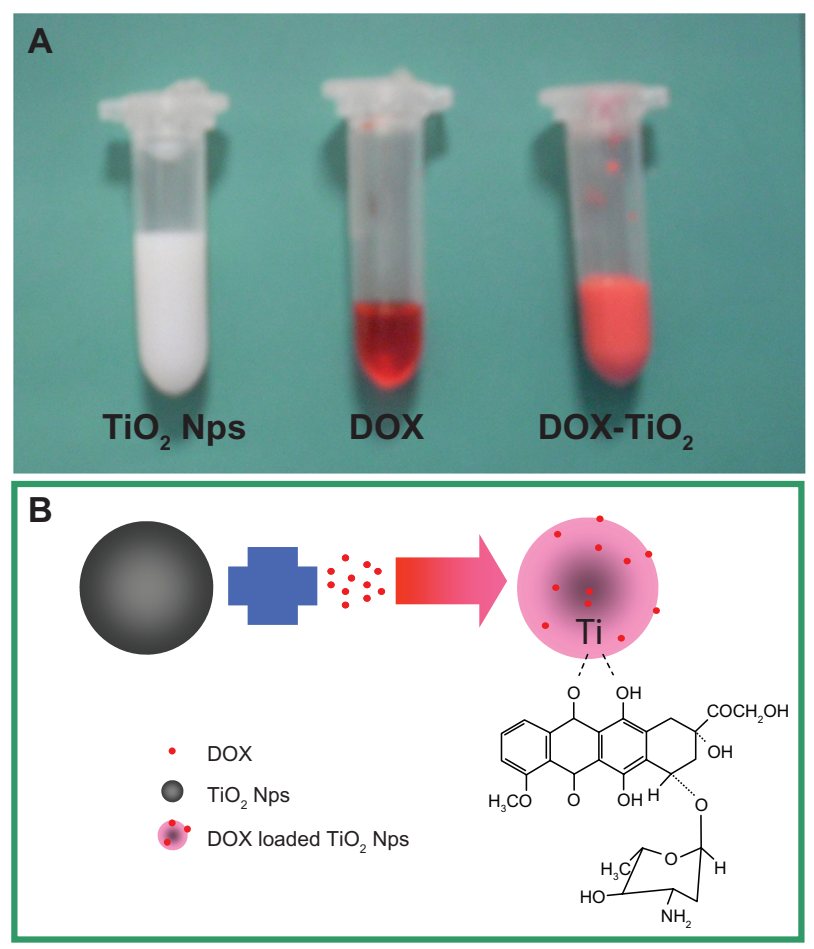

Figure 3 Photographic image $(\mathbf{A})$ and the schematic representation (B) of doxorubicin loading onto the $\mathrm{TiO}_{2}$ nanoparticles through the formation of DOX$\mathrm{TiO}_{2}$ nanocomposites.

Abbreviations: $\mathrm{DOX}$, doxorubicin; $\mathrm{TiO}_{2}$, titanium dioxide; $\mathrm{Nps}$, nanoparticles. 
onto the $\mathrm{TiO}_{2}$ nanoparticles. In addition, the surface charge is an important physicochemical property of nanomaterials, and the zeta potential is the common indicator. The zeta potential of the $\mathrm{TiO}_{2}$ nanoparticles $(10 \mu \mathrm{g} / \mathrm{mL})$ was negative $(-26 \mathrm{mV})$ in pH 7.4 aqueous solution. When doxorubicin was loaded onto the $\mathrm{TiO}_{2}$ nanoparticles, the zeta potential decreased to $-5 \mathrm{mV}$, indicating that doxorubicin can easily self-assemble onto the surface of $\mathrm{TiO}_{2}$ nanoparticles by electrostatic interaction. The encapsulation efficiency and loading efficiency of the doxorubicin-loaded $\mathrm{TiO}_{2}$ nanoparticles was assessed and calculated to be $60.46 \% \pm 6.53 \%$ and $20.08 \% \pm 2.14 \%$, respectively. The results show that $\mathrm{DOX}-\mathrm{TiO}_{2}$ nanocomposites may act efficiently as an anticancer drug delivery carrier.

\section{Anticancer efficacy enhancement and side effect attenuation}

To explore further the anticancer efficiency of the novel drug delivery system based on $\mathrm{DOX}-\mathrm{TiO}_{2}$ nanocomposites, we cultured human hepatocarcinoma SMMC-7721 cells with free doxorubicin at different concentrations $(0,0.125,0.25$, 0.5 , and $1 \mu \mathrm{g} / \mathrm{mL}$ ) and with $\mathrm{DOX}-\mathrm{TiO}_{2}$ nanocomposites with equivalent doxorubicin concentrations for 48 hours. Cytotoxicity was estimated by MTT assay and is shown in Figure 4. Cytotoxicity testing of a nanomaterial is the firstlevel evaluation before its biomedical application. When treated by $\mathrm{TiO}_{2}$ nanoparticles $(10 \mu \mathrm{g} / \mathrm{mL})$, about $95 \%$ of the cells survived (Figure 4, red line), which is consistent with our previous report. ${ }^{15}$ This result suggests lack of cytotoxicity for $\mathrm{TiO}_{2}$ nanoparticles, thus ensuring a wide potential range of applications in the field of biomedical science and cancer therapy. Compared with doxorubicin alone (Figure 4, pink line), the viability of SMMC-7721 cells treated by $\mathrm{DOX}-\mathrm{TiO}_{2}$

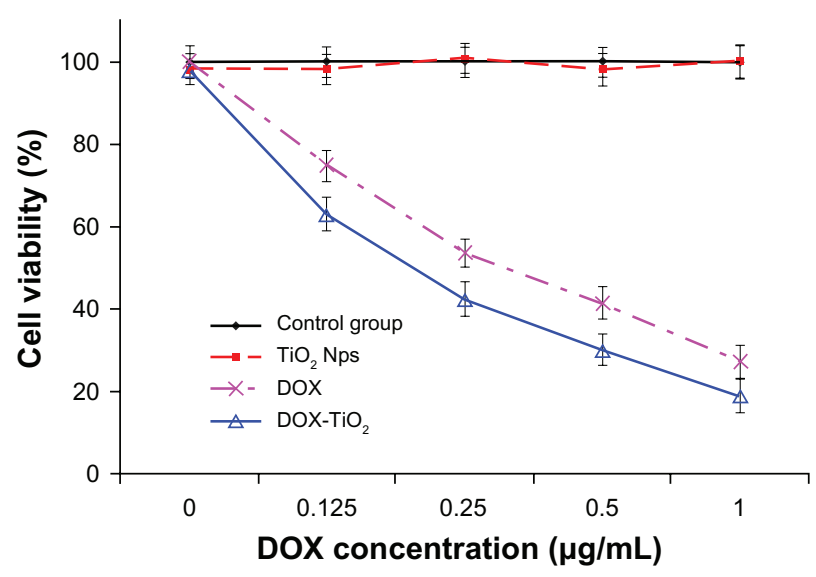

Figure 4 Cytotoxic effect of doxorubicin or $\mathrm{DOX}_{-} \mathrm{TiO}_{2}$ nanocomposites against the human SMMC-772I hepatocarcinoma cells.

Note: Data expressed as the mean \pm standard deviation $(n=3)$.

Abbreviations: $\mathrm{DOX}$, doxorubicin; $\mathrm{TiO}_{2}$, titanium dioxide; $\mathrm{Nps}$, nanoparticles. nanocomposites markedly decreased (Figure 4, blue line). Our results also indicate that lethality increases with increasing concentrations of DOX, suggesting a dose-dependent effect in vitro. This increased cytotoxicity may be due to improved doxorubicin cellular uptake by $\mathrm{DOX}-\mathrm{TiO}_{2}$ nanocomposites through the endocytosis pathway, which is a common characteristic of nanoparticle-based drug delivery systems. ${ }^{17}$ Therefore, a sufficiently high concentration of doxorubicin can be generated within tumor cells by $\mathrm{TiO}_{2}$ nanoparticles, thereby greatly promoting the cytotoxic effects.

The $\mathrm{IC}_{50}$ value, ie, the concentration of a drug that inhibits cell growth by $50 \%$ in different treatments, was determined from the above dose response. As shown in Figure 5, the $\mathrm{IC}_{50}$ value for free doxorubicin in the tumor cells was $0.32 \mu \mathrm{g} / \mathrm{mL}$, and $\mathrm{DOX}-\mathrm{TiO}_{2}$ nanocomposites could alter the $\mathrm{IC}_{50}$ value to $0.20 \mu \mathrm{g} / \mathrm{mL}$. Considering that a high dose of doxorubicin may lead to serious side effects, especially congestive heart failure, ${ }^{2}$ the lower $\mathrm{IC}_{50}$ for the $\mathrm{DOX}-\mathrm{TiO}_{2}$ nanocomposite drug delivery system could improve therapeutic efficacy without high usage of doxorubicin and minimize its toxic side effects.

\section{Expression of $\mathrm{Bax}, \mathrm{Bcl}-2$, and caspase 3 proteins}

Nuclear DNA is the main subcellular site of doxorubicin action for its antitumor activity. Doxorubicin can efficiently accumulate in the cell nucleus, intercalate DNA, and act as a cytostatic and apoptotic agent in tumor cells. The production of free radicals and oxidative stress is also closely involved in the action of doxorubicin, in terms of both anticancer and toxic effects. ${ }^{18}$ To explore the possible signaling pathways through which $\mathrm{DOX}-\mathrm{TiO}_{2}$ nanocomposites enhance anticancer efficacy and attenuate side effects, we examined changes in the expression levels of apoptosis-regulating proteins, including Bax, Bcl-2, and caspase 3, by Western blot. As shown in Figure 6,

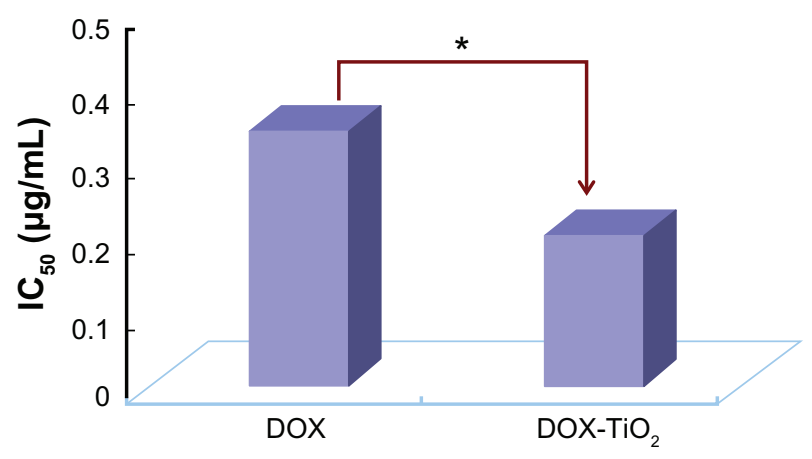

Figure 5 The $\mathrm{IC}_{50}$ of DOX, DOX-TiO 2 nanocomposites for SMMC-772I cells. Note: $* P<0.05$, compared with free DOX.

Abbreviations: $\mathrm{DOX}$, doxorubicin; $\mathrm{DOX}-\mathrm{TiO}_{2}$, titanium dioxide-doxorubicin nanocomposites. 
A

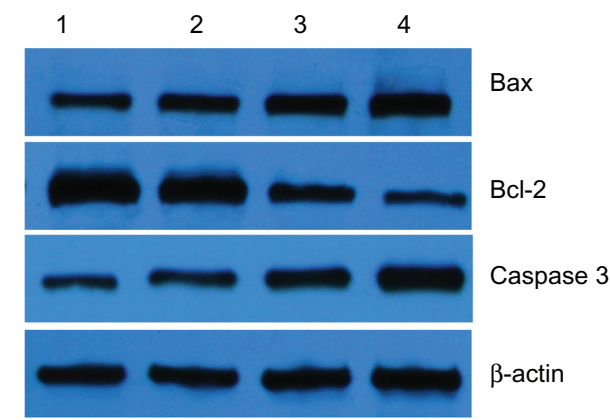

B

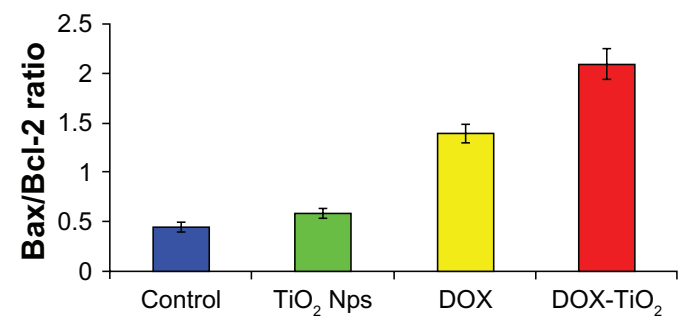

Figure 6 Expression of $\mathrm{Bax}, \mathrm{Bcl}-2$, and caspase 3 protein $(\mathbf{A})$ and the $\mathrm{Bax} / \mathrm{Bcl}-2$ ratio (B) in the human SMMC-772I hepatocarcinoma cells by Western blot after treatment with doxorubicin and/or $\mathrm{TiO}_{2}$ nanoparticles for 48 hours. Line I, control; line 2, incubated with $10 \mu \mathrm{g} / \mathrm{mL} \mathrm{TiO}_{2}$ nanoparticles; line 3, incubated with $0.5 \mu \mathrm{g} / \mathrm{mL}$ doxorubicin; line 4 , incubated with $0.5 \mu \mathrm{g} / \mathrm{mL}$ doxorubicin and $10 \mu \mathrm{g} / \mathrm{mL} \mathrm{TiO}$, nanoparticles. Abbreviations: $\mathrm{DOX}$, doxorubicin; $\mathrm{TiO}_{2}$, titanium dioxide; $\mathrm{Nps}$, nanoparticles.

when the human SMMC-7721 hepatocarcinoma cells were treated with doxorubicin and $\mathrm{DOX}-\mathrm{TiO}_{2}$ for 48 hours, levels of Bax and caspase 3 protein were significantly upregulated compared with the other groups. Meanwhile, levels upregulated by $\mathrm{DOX}-\mathrm{TiO}_{2}$ were slightly higher than those upregulated by doxorubicin $(P<0.05)$. However, they were not obviously altered when the cells were treated with $\mathrm{TiO}_{2}$ nanoparticles alone $(P>0.05)$. In contrast, compared with the control group, levels of Bcl-2 protein in cells treated with doxorubicin and $\mathrm{DOX}-\mathrm{TiO}_{2}$ were both significantly downregulated. Furthermore, the level of Bcl-2 in cells treated with $\mathrm{DOX}-\mathrm{TiO}_{2}$ was lower than that in cells treated with doxorubicin, and was not obviously altered when the cells were treated with $\mathrm{TiO}_{2}$ nanoparticles alone $(P>0.05)$. The ratio of $\mathrm{Bax} / \mathrm{Bcl}-2$ protein expression increased dramatically when the SMMC-7721 cells were treated with $\mathrm{DOX}-\mathrm{TiO}_{2}$ nanocomposites in our study.

Sensitivity of cells to an apoptotic stimulus is determined by the relative ratio of proapoptotic and antiapoptotic members of the Bcl-2 family, ie, the mitochondrial-related death switch. ${ }^{19}$ Upregulated Bax leads to disruption of the integrity of the mitochondrial membrane, resulting in caspase 3 activation. Caspase activation is generally considered to be the hallmark of apoptosis, and caspase 3 is the main effector caspase that is involved in apoptosis. ${ }^{20}$ Thus, the ratio of Bax/Bcl-2 might be a critical factor in the cell threshold for undergoing apoptosis induced by $\mathrm{DOX}-\mathrm{TiO}_{2}$. These findings strongly suggest that $\mathrm{DOX}-\mathrm{TiO}_{2}$ nanocomposites enhance anticancer efficacy and reduce side effects by inducing apoptosis in a caspase-dependent manner.

Figure 7 schematically illustrates the possible processes by which this novel drug delivery system based on $\mathrm{TiO}_{2}$ nanoparticles conjugated with doxorubicin enhances anticancer efficacy and attenuates side effects. Firstly, doxorubicin can be easily self-assembled onto the surface

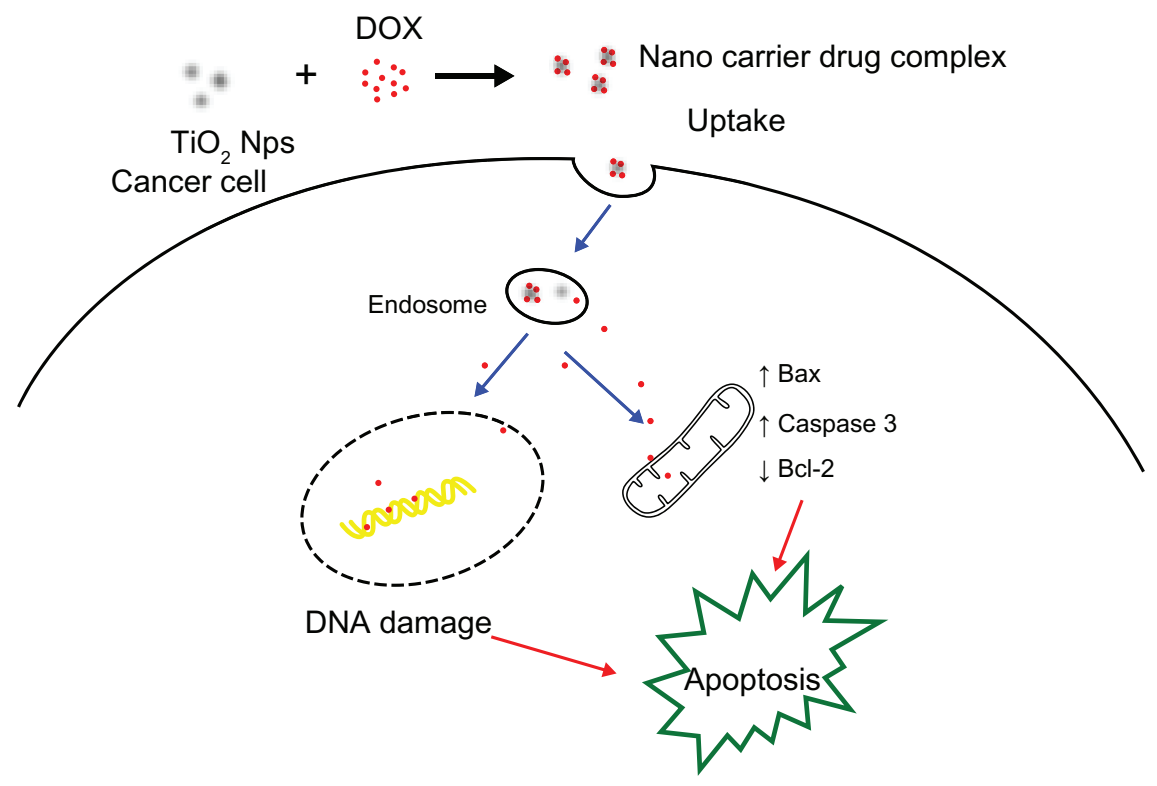

Figure 7 Schematic illustration of the possible process of the anticancer efficacy enhancement and side effect attenuation by the drug delivery system based on $\mathrm{TiO}_{2}$ nanoparticles for DOX.

Abbreviations: DDS, drug delivery system; $\mathrm{TiO}_{2}$, titanium dioxide; $\mathrm{DOX}$, doxorubicin; Nps, nanoparticles. 
of $\mathrm{TiO}_{2}$ nanoparticles by forming complexes with titanium, a transition metal. In this way, $\mathrm{TiO}_{2}$ nanoparticles can load large amounts of doxorubicin molecules and carry them into cells, increasing the intracellular concentration of doxorubicin dramatically, thus enhancing the suppression of proliferation of the cancer cells. Therefore, this drug delivery system increases the therapeutic concentration of doxorubicin inside cancer cells, enhancing the efficiency of the drug dose, decreasing the $\mathrm{IC}_{50}$, and accordingly attenuating side effects, which indicates tremendous potential for application in cancer therapy. Apoptosis, the preferred therapeutic mode for killing cancer cells, is induced synergistically, resulting in marked improvement in anticancer activity.

\section{Conclusion}

In this study we developed a drug delivery system formulated by self-assembly of doxorubicin and $\mathrm{TiO}_{2}$ nanoparticles. The $\mathrm{DOX}-\mathrm{TiO}_{2}$ nanocomposites increased the accumulation of doxorubicin in tumor cells, resulting in enhanced anticancer activity by inducing apoptosis in a caspase-dependent manner, with attenuation of the toxic side effects of doxorubicin. These characteristics show that this novel drug delivery system based on $\mathrm{TiO}_{2}$ nanoparticles conjugated with doxorubicin is a promising strategy for future clinical practice.

\section{Acknowledgments}

This study was supported by grants from the Natural Science Foundation of China $(30872335,81172871)$ and Technology Development Foundation of Jiangsu Province Department of Health (H200950).

\section{Disclosure}

The authors report no conflicts of interest in this work.

\section{References}

1. Zheng J, Lee, HCM, bin Sattar MM, Huang Y, Bian JS. Cardioprotective effects of epigallocatechin-3-gallate against doxorubicin-induced cardiomyocyte injury. Eur J Pharmacol. 2011;562:82-88.

2. Ibsen S, Zahavy E, Wrasdilo W, Berns M, Chan M, Esener S. A novel doxorubicin prodrug with controllable photolysis activation for cancer chemotherapy. Pharm Res. 2010;27:1848-1860.
3. Yousefpour P, Atyabi F, Farahani EV, Sakhtianchi R, Dinarvand R. Polyanionic carbohydrate doxorubicin-dextran nanocomplex as a delivery system for anticancer drugs: in vitro analysis and evaluations. Int J Nanomedicine. 2011;6:1487-1496.

4. Jeong YI, Kim DH, Chung CW, et al. Doxorubicin-incorporated polymeric micelles composed of dextran-b-poly(DL-lactide-co-glycolide) copolymer. Int J Nanomedicine. 2011;6:1415-1427.

5. Li C, Wallace S. Polymer-drug conjugates: recent development in clinical oncology. Adv Drug Deliv Rev. 2008;60:886-898.

6. Jannesari M, Varshosaz J, Morshed M, Zamani M. Composite poly(vinyl alcohol)/poly(vinyl acetate) electrospun nanofibrous mats as a novel wound dressing matrix for controlled release of drugs. Int $J$ Nanomedicine. 2011;6:993-1003.

7. Chen BA, Mao PP, Cheng J, et al. Reversal of multidrug resistance by magnetic $\mathrm{Fe}_{3} \mathrm{O}_{4}$ nanoparticle copolymerizating daunorubicin and MDR1 shRNA expression vector in leukemia cells. Int J Nanomedicine. 2010;5:437-444.

8. Wu WW, Chen BA, Cheng J, et al. Biocompatibility of $\mathrm{Fe}_{3} \mathrm{O}_{4} / \mathrm{DNR}$ magnetic nanoparticles in the treatment of hematologic malignancies. Int J Nanomedicine. 2010;5:1079-1084.

9. Wang J, Chen BA, Cheng J, et al. Apoptotic mechanism of human leukemia K562/A02 cells induced by magnetic iron oxide nanoparticles co-loaded with daunorubicin and 5-bromotetrandrin. Int J Nanomedicine. 2011;6:1027-1034.

10. Wang J, Chen BA, Cheng J, et al. Synthesis and antitumor efficacy of daunorubicin-loaded magnetic nanoparticles. Int J Nanomedicine. 2011;6: 203-211.

11. Zhang HJ, Chen BA, Jiang H, Wang CL, Wang HP, Wang XM. A strategy for $\mathrm{ZnO}$ nanorod mediated multi-mode cancer treatment. Biomaterials. 2011;32:1906-1914.

12. Barick KC, Nigam S, Bahadur D. Nanoscale assembly of mesoporous ZnO: A potential drug carrier. J Mater Chem. 2010;20:6446-6452.

13. Song M, Zhang RY, Dai YY, et al. The in vitro inhibition of multidrug resistance by combined nanoparticulate titanium dioxide and UV irradiation. Biomaterials. 2006;27:4230-4238.

14. Li QN, Wang XM, Lu XH, et al. The incorporation of daunorubicin in cancer cells through the use of titanium dioxide whiskers. Biomaterials. 2009;30:4708-4715.

15. Zhang HJ, Jiang H, Wang HP, Zhao J, Chen BA, Wang XM. Ultrasound mediated drug-loaded nanoparticles crossing cell membranes as a new strategy to reverse cancer multidrug resistance. J Nanosci Nanotechnol. 2011;11:1834-1840.

16. Zhang DW, Zhang H, Nie J, Yang J. Synthesis and self-assembly behavior of pH-responsive amphiphilic copolymers containing ketal functional groups. Polym Int. 2010;59:967-974.

17. Yoo HS, Lee $\mathrm{KH}, \mathrm{Oh} \mathrm{JE}$, Park TG. In vitro and in vivo anti-tumor activities of nanoparticles based on doxorubicin-PLGA conjugates. J Control Release. 2000;68:419-431.

18. Granados-Principal S, Quiles JL, Ramirez-Tortosa CL, Sanchez-Rovira P, Ramirez-Tortosa MC. New advances in molecular mechanisms and the prevention of adriamycin toxicity by antioxidant nutrients. Food Chem Toxicol. 2010;48:1425-1438.

19. Yang E, Korsmeyer SJ. Molecular thanatopsis: A discourse on the BCL2 family and cell death. Blood. 1996;88:386-401.

20. Ghavami S, Hashemi M, Ande SR, et al. Apoptosis and cancer: Mutations within caspase genes. J Med Genet. 2009;46:497-510.
International Journal of Nanomedicine

\section{Publish your work in this journal}

The International Journal of Nanomedicine is an international, peerreviewed journal focusing on the application of nanotechnology in diagnostics, therapeutics, and drug delivery systems throughout the biomedical field. This journal is indexed on PubMed Central, MedLine, CAS, SciSearch ${ }^{\circledR}$, Current Contents ${ }^{\circledR} /$ Clinical Medicine,

\section{Dovepress}

Journal Citation Reports/Science Edition, EMBase, Scopus and the Elsevier Bibliographic databases. The manuscript management system is completely online and includes a very quick and fair peer-review system, which is all easy to use. Visit http://www.dovepress.com/ testimonials.php to read real quotes from published authors. 